\title{
Barriers to Rural Community Participation in Solid Waste Management Programmes at the Asunafo North District in Brong Ahafo Region of Ghana
}

\author{
Agnes Tweneboah Mensah \\ Department of Environment and Resource Studies \\ Faculty of Integrated Development Studies \\ University for Development Studies, Wa Campus, Ghana \\ Tel: 233-504-845-800Ｅ-mail: agnesb23.nm@gmail.com \\ Dr. Nicodemus Osei Owusu \\ Department of Management Studies, School of Business \\ University of Cape Coast, Ghana
}

Tel: 233-502-560-234Ｅ-mail: nowusu@ucc.edu.gh

Received: January 4, 2019 Accepted: January 15, 2019 Published: April 24, 2019

doi:10.5296/emsd.v8i2.14144 URL: https://doi.org/10.5296/emsd.v8i2.14144

\begin{abstract}
For many years now, solid waste problem has become of the major environmental issue which has confronted various Africa local authorities and Ghana has not been an exception. While various communities have been encouraged to participate in solving the problem, in Ghana, little or no success story about community participation in solid waste management (SWM) programmes can be demonstrated. This study consequently sought to investigate into the barriers to rural community participation in SWM Programmes at the Asunafo North district in Brong Ahafo region of Ghana. Qualitative case-study method was employed with in-depth interviews and focus groups discussions techniques used to ascertain the opinions of the community members and environmental health officials themselves. Data were audio-taped, transcribed and later analysed. The study finding indicated that a number of barriers prevent community members from participating in SWM which include: lack of support, disillusionment, culture and poverty emanating from high cost of living and precarious nature of the communities' livelihoods. It is therefore recommended that for the communities to be
\end{abstract}


motivated to participate in SWM propgrammes there should be practical supports in all kinds from the various stakeholders such as the municipality, community-based organisations, micro enterprises and local leaders.

Keywords: Barriers, Rural communities, Solid waste management, Programmes, Ghana

\section{Introduction}

For many years now, solid waste problem has been an issue which has confronted various Africa local governments' authorities that have been charged with the responsibilities of ensuring better sanitation in their localities. With the growth of the population, the pressure on local authorities on the management of solid wastes has become so unbearable that most municipal authorities could collect and dispose off only $20 \%-30 \%$ of the generated solid waste (Chinamo, 2003). Implicitly, $80 \%-70 \%$ of the solid waste has mostly been left uncollected resulting in production of smoke from burning of solid waste, frequent inhaling of disgusting odor from decomposed waste, contamination of drinking water sources and outbreaks of diseases like cholera in countries like Ghana (Peprah, Amoah \& Achana, 2015). What is worsening this situation is the world's urban population which grows by two new-born babies every second with 95 percent of such increases occurring in cities of developing economies (Hoornweg \& Perinaz, 2012; Oteng-Ababio, 2014).In addition, the growth of poverty and a mass movement of local citizens from the rural areas into towns have worsened the waste management challenges creating huge environmental problems in most district capitals in the developing countries (Srinivas, 2003, Sinha \& Enayetullah, 2000a). What is more worrying is the fact a number of waste producers avoid the task of solid waste management and often succeed in putting the real responsibility on both the local and municipal authorities alone causing these authorities to bear the huge cost of managing solid waste (Hoornweg \& Perinaz, 2012),

In Ghana, with its attempt to address this problem, since 2011, the government has adopted the '3Rs' or 'RRR', that is, 'reduce, reuse and recycle' strategy to provide policy directives to authorities to solve the solid waste menace (Peprah, Amoah \& Achana, 2015). This has consequently gained large support from legal backing following the promulgation of the Local Government Act (Act 462) (Ministry of Local Govt and Rural Development, MLGRD, 2012). Inherent in this 3-tier-R has been six hierarchical steps: prevention, reduction, reuse, recycle, energy recovery and disposal. It is expected that a careful implementation of such a policy strategy would stimulate conversion of solid wastes into new resources, minimising environmental pollution and enhance natural resource exploitation (Zhu, Asnani, Zurbrugg, Anapolsky, \& Mani (2008). From the points of view of experts like Wu, Shia, \& Xiaa (2014) and Zaman, (2014), considering the fact that such a management system demands collective responsibility, techniques and actions as well as monitoring and evaluation, sustainable solid waste management needs to be built around stakeholder participation. This will involve the inclusion of integrated and sustainable approaches. In addition, Zarate, Slotnick, \& Ramos, (2008) opined that besides public participation and empowerment, the main elements to the success of such a programme are decision transparency, networking, co-operation and collective action, communication, and accessibility of information. The idea here is that the 
'3Rs' model must involve consensus building among various stakeholders such as communities, public officials, community based organizations (CBOs), non-governmental organizations (NGOs), as well as external support agencies (ESAs) (UNEP, 2011; Schubeler, Wehrle, \& Christen, 1996).

Thus, there has been a general realization that this burden demands a collaborative action and without the help from other stakeholders, the local authorities alone will not be able to offer all the needed services to achieve their goal of alleviating the threat of the solid waste management. Notwithstanding these efforts, while there have been many successful cases (Iyer and Anjana 2001; Saldana \& Dubois, 2006; Cofie, 2006) in developing countries about community participation in waste management, in Ghana, little or no such success story can be demonstrated. This poses a serious question "what are the barriers to community participation in Solid Waste Management Programmes in Ghana?"

It is in the light of this that this study is conducted with the purpose of investigating into the barriers to community participation in solid waste management (SWM)

On the basis of the above study aim, the rest of the study will be addressed as follows: The first part is about literature review with discussions on the significance of the study, the concepts of community participation and solid waste management. The second part addresses the methodology of the study while the third section deals with the study findings. The final section addresses the study conclusions and recommendations.

\section{The Study's Contribution to Research, Practice and Knowledge}

Through this original examination on the barriers to community participation in SWM, the intricacies of understanding the practical challenges facing communities in their attempt to participate in SWM have been uniquely demonstrated in both the regional and particularly district context in Ghana. In addition, whilst generalisation from case study research is usually questionable, as the macro context for all districts' SWM practices are very similar, it can be said that the research framework created is transferable to other locations. The findings from this study have also significantly contributed to knowledge in the subject of community participation in the SWM practices and in the Ghanaian context. Given that community participation is context-specific, that the very nature of communal attitude and perceptions are unique in itself, and that the historic, political and economic drivers for community participation in the Africa are different to those in other developing or developed countries, warrants that research in this Africa context is conducted. In so doing, the study findings uniquely investigate theoretical debates that inhibit the use of governance principles and the power of social capital to encourage community participation in local SWM practices. Thus, theoretically, the study can be used as a stepping stone for future researchers who will be interested in this study area as it will contribute to knowledge in the field of SWM. From a practical perspective, the study can act as a good source of information to the decision makers not only in Local Government Authorities (LGAs) but also other stakeholders like NGOs on issues regarding SWM. From this study, stakeholders will become aware of the fundamental reasons associated with lack of community participation in SWM. With this realization, the stakeholders will be in a better position to put in place measures that can motivate community 
members to be involved in SWM which will help the LGAs to keep clean environment and manage domestic solid waste sources. This will improve sanitation and enhance the healthiness of the community.

\section{Literature Review}

\subsection{The Concept of Community Participation}

Agudelo (1983) has defined "community" as a group of people living in a particular area with similar values, cultural patterns, and social problems. This also includes a group awareness which make it easier for the residents to interact more deeply with each other than those from outside. With Agudelo's definition, location and culture are significant factors that determine community. In support of this, Cohen and Syme (1985) have the view that 'community' has to be defined based on its use and role in people's experience, according to what the members have in common with each other and how they symbolically differentiate themselves from others. For Rifkin (1986), community refers to 'at risk' groups or target populations whose identity is based on the features they share and experience in common with each other.

Despite these apparent differences, it can be argued that there is a common theme that can be derived from these definitions. In general, in a study by MacQueen et al. (2001), five core elements were identified. The first among them was the locus, a sense of place, which referred to a geographic entity starting from neighborhood to city size, or a specific milieu around which people gathered (such as a church or recreation center). The second was sharing, common interests and perspectives, which referred to general interests and values that could cross geographic boundaries. The third was joint action, a sense of coherence and identity, including informal common activities such as sharing tasks and helping neighbors, but these were not essentially deliberately planned to produce community cohesion. The fourth was social ties which involved associations that produced the ongoing sense of cohesion. The last was the diversity which referred not mainly to ethnic groupings, but to the social complexity within communities in which a collection of communities co-existed.These explanations supports earlier arguments made by Hawe (1994) who epitomises the description of a community as a social system, which has a:

\section{“.. Capacity to work towards solutions to its own community identified problems.” (p. 201).}

Thus community can be understood as the existence of people with common interest and ties which induce individuals to act for the communal gains (Anderson, 1991). Community in this study is therefore considered as a group of people living in a particular place as grassroots members who are united by one common interest (e.g. managing SWM). It is this common interest that brings them together with the aim of collectively finding a solution to the problem.

In respect to participation, Labonte (1997) considers it as a process of trying to ensure the coming together of stakeholders of diverse background whose aim is to make a decision that will help them solve a problem. Similar view is also shared by Campbell \& Jovchelovitch, (2000) who argue that participation provide a platform for dialogue amongst participants who can express, reaffirm and renegotiate what concern them. Thus in the context of decision 
making, according to Parry et al. (1992), participation must involve:

"taking part in the process of formulation, passage, and implementation of public policies [through] action by citizens which is aimed at influencing decisions which are, in most cases, ultimately taken by public representatives and officials" (p 16).

The underlying idea in this definition is that the success and sustainability of community participation in health and development projects depends on the degree to which community ownership and empowerment are realised (Kaseje \& Sempebwa, 1989). However, irrespective of how community participation is defined, the essence of community is that something is "shared" and community participation can be considered as a process along a continuum which helps communities to make the most of their potentials and progress from individual action to collective social and political change (Butterfoss, 2006).

As far as this study is concerned, community participation should be seen to be creating an enabling environment by the authorities for the community members to directly develop a change of behaviour that will help in managing SWM. This means going beyond simple consultation to a shared responsibility for resolving problems within the community. Thus, community participation is considered to have taken place where grassroots community members are given the chance to work together to develop and implement policy programmes in SWM. The underlying justification for the need for the involvement of the communities is that such participation would encourage the members to solve their own common problems themselves as well as deciding about issues that affect their daily lives (Morrissey \& Browne, 2004). This will also assist them to become agents of their own development rather than being positive beneficiaries of free services. Howlett \&Nagu (2001) also argued that participation is one of the critical components of success as it is connected with growing mobilization of possession of polices and project; greater efficiency, creation of social cohesion, increasing empowerment and strengthened capacity of the people to learn and act.

\section{Solid Waste Management (SWM)}

SWM is considered to be an organized treatment of waste materials from source through recovery processes to disposal (Chirico, 2009). Daskalopoulos, Badr, \& Probert ( 1999) and Lin, Huang, Lu, \& He, (2008) are also of the view that SWM involves control of generation, storage, collection, transportation, processing and disposal of solid waste with the intention of protecting environmental quality, human health and safeguarding the natural resources. Furthermore, Zhu, Asnani, Zurbrugg, Anapolsky, \& Mani, (2008) note that solid waste refers to non-liquid material that is no more worth to the owner which can include rubbish, garbage, trash, or refuse. For instance kitchen waste, paper products, rags, plastics, rubber, leather, bone, glass, crockery, pots, sweepings, metal and old furniture (Shakya \& Tuladhar, 2014). These are often produced by households, offices, hotels, shopping complexes/shops, markets, yards, schools, institutions and street cleaning (Borongan, \& Okumura, 2010). These wastes have been categorized by UNEP, (2011) as household/domestic, commercial, institutional, industrial and agricultural waste with the exclusion of semisolid waste such as sludge and night-soil (liquid waste) and clinical waste produced by hospitals (Schubeler, Wehrle, \& 


\section{N Macrothink}

Christen, 1996). In the light of this, Al-Maaded, Madi, Kahraman, Hodzic, \& Ozerkan (2011) are of the view that, solid waste management that is carried out alongside the lines of an orderly use of reducing, reusing and recycling depends on managerial procedures, practical choices and state-of-the-art strategies. Lenox \& King (2004) have also come to realise that successful reduction, reusing and recycling of waste are accomplished with the support of appropriate equipment and use of qualified personnel. On the other hand, the opposite is true that inexperience personnel reduces the success rate (Lapre, Mukherjee, \& Van Wassenhove 2007), whereas scarce equipment for waste crushing or refining processes disrupts the process (Field, \& Sroufe, 2007).

\section{Study Method}

\subsection{Study Design}

This research is an explorative study and therefore has employed a case study as an approach of investigation. A case study, from the view of Creswell (1998), is not only an exploration, but a thorough analysis of circumscribed systems, controlled by time or place with such a case study being either a process, activity or of people. The examination of the case occurs by way of detailed means of data collection methods which can be interviews and observations. With this study, the case study took place from May 2018 until end of July 2018 in the Asunafo North district

Qualitative data collection techniques were employed for this research study. The use of this study design is based on the point of view of Denzin \& Lincoln (2000) who assert that qualitative research helps a researcher to understand phenomena in its natural surroundings as it is a field of naturalistic investigation that cuts across many disciplines and subject matters. In addition, these two writers agree to the idea that qualitative research is characterised by several methods that have the abilities to use an interpretive and naturalistic approach to address issues under investigation.

\subsection{Study Area}

The study was conducted in Asunafo North District as in figure 1 below. This is one of the twenty-seven (27) administrative districts in the Brong Ahafo Region of Ghana with its capital at Hwidiem. This district was selected because it is one of the districts in the Brong Ahafo region which, according to the Regional Annual Report (2016) has low involvement of community participation in SWM programme activities compared to most of the districts in the region. 


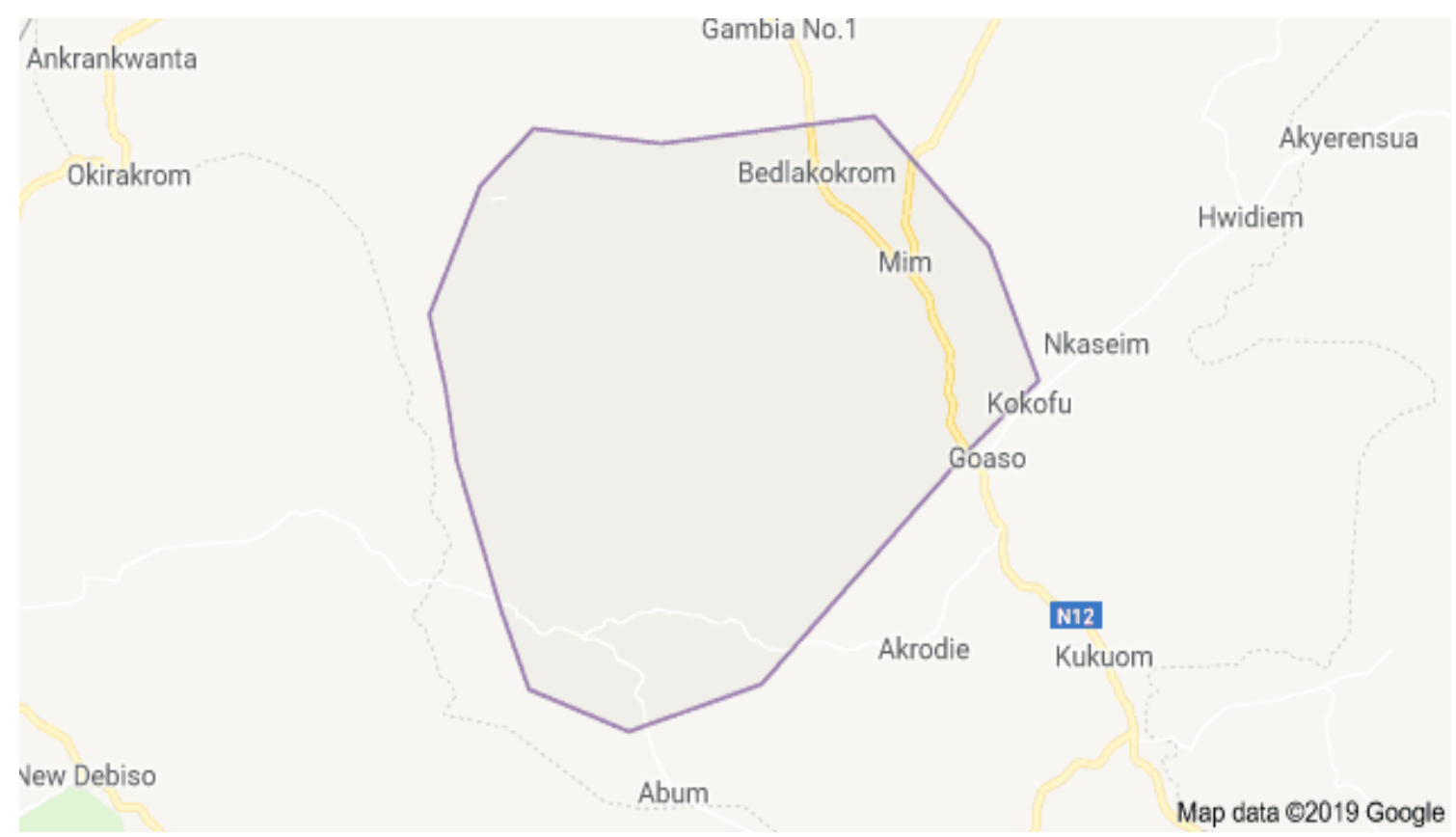

Figure 1. Asunafo North District- Location of the study

\section{Source:}

https://www.google.com/search?client=firefox-b-d\&q=map+of+Asunafo+North+District+in+ Ghana

According to the Ghana Statistical Service of District Analytical Report, (2014) the population of the district was 124,685 representing 5.4 percent of the region's total population. Males constitute 50.4 percent while the percentage number of females is 49.6. 60 percent of the population is rural and out of the employed population, 60.3 percent are engaged as skilled agricultural, forestry and fishery workers, 13.4 percent in service and sales and 1.7 percent are engaged as managers, professionals, and technicians. Households involved in agriculture in the district stands at 71.8 percent. In the rural localities, 85.9 percent households and urban $(51.1 \%)$ are agricultural households.

\subsection{Study Population}

The population of the study included mostly elected community members at the local levels of the district while others were ordinary community members. The former were purposively selected while the latter were conveniently sampled based on the willingness of the person to take part in the study. In all, the total population size was 30 individuals with 6 being community leaders who were interviewed face to face. The other 24 were ordinary community members who formed part of the focus group discussions (FGD).

In this study the authors did not collect any comments from authorities due to the fact that in the health policy field as well as programme activities, the different actors have its own interests and power (Ham, 1999) and although these health officials are living within the communities, they are not purely members. This is because they are not faced with the same risks as the rest of the community members. Their socio-economic background is different 
from the local community members themselves as such what the communities may see as a problem, the officials will see it differently. Moreover, the officials work for the government whose job is to defend the state and as such there are often unequal power dynamics causing difficulties in making them see the SWM problem in the same way as the community themselves see it. Thus, when it comes to SWM, the government representatives' perceptions may be different from the local community members since the former may be biased towards the barriers whose cause can be blamed on the government. E.g. lack of provision of dust bins or waste materials. Hence, the exclusions of the government's officials from the interview

\subsection{Data Collection Tools}

With regards to the data collection tools, besides document review, two main tools were used and these included the face to face interviews and FGD. The use of the latter method to support the former was supported by Krueger, (1988) who claimed that FGD has the verve of expediency, economic benefit, high level of legitimacy, and prompt outcomes. Other writers such as Merton et al., (1990), and Morgan, (1996) also opined that FGD is useful because of its decisive exploitation of social contact in producing data.

FGD were carried out at various places within the district since the community members were not at one place. Four discussions were held with each group made up of 6 members comprising both males and females with ages ranging from 18 to 66. The key objective of the FGD was to discover in details the views of community members on the barriers to their participation in SWM in their area. For the sake of anonymity each interviewee was given a number instead of their personal names and this has been indicated after each quote in the study.

\subsection{Data Analysis}

In analysing the data, the information gathered were transcribed before the thematic approach was used in this study. Data were coded devoid of basically preconceived ideas of researchers on the data. An inductive approach was employed to discover the themes as they became known from the data. The data were analysed without the use of any technological means, rather it was done manually by reading and having a second look at the transcripts until the content was well comprehended. Appraising the transcripts was done concurrently with coding the data by putting down expressions that take into account the concepts that come out. With the emerged concepts, further scrutiny was made based on the study objective to categorize as well as discern the key themes that cropped up.

\section{Study Results}

From the interviews, four main factors were found to be the barriers to the community participation to the SWM as it can be seen from the Figure 2 below. From the figure, it could be noted that the four main barriers were: and these included: lack of local authority support, disillusionment among the members, culture and poverty as discussed in details below. 


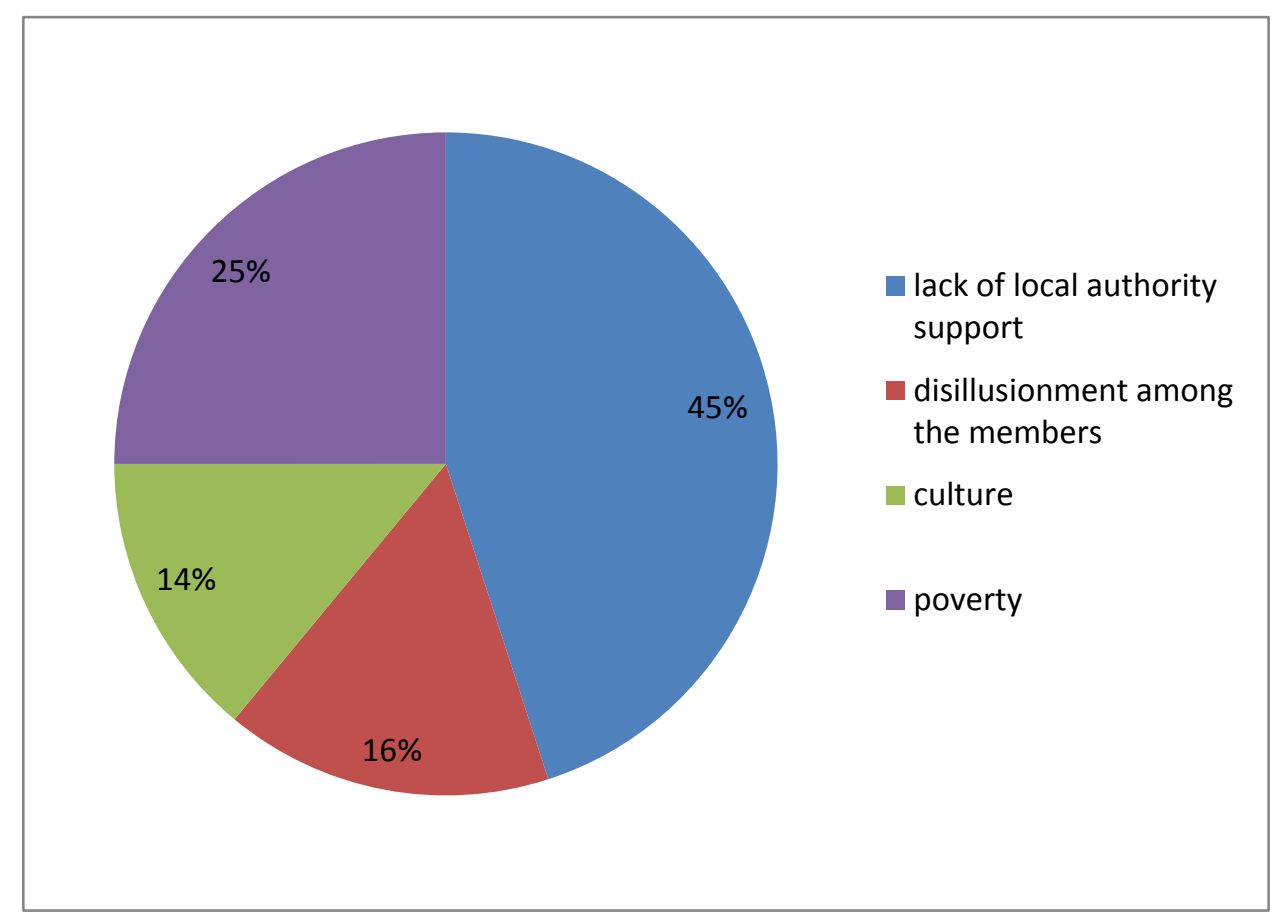

Figure 2. Four Main Barriers to Community participation to SWM

The interviewees' comments made on the barriers have also been shown in Table 1 below

Table 1. The comments from the interviewees on the barriers

\begin{tabular}{|l|l|}
\hline BARRIERS & INTERVIEWEES' COMMENTS \\
\hline authority support & $\begin{array}{l}1: \ldots . \text { "I do not think the health officials have done anything to motivate } \\
\text { us. We do not know what is going on. No educational campaign so most } \\
\text { of us don't know what role we have to play (Nr 12) } \\
\text { 2....."We hardly get their support in terms of educational campaign but } \\
\text { I believe to motivate these our people to take part in these activities, } \\
\text { there should be continuous education to inform us about the importance } \\
\text { of SWM" (Nr 6) ...... } \\
3 \text {..These days the health officials do not care about us and the distance } \\
\text { between us and them is widening every day. They do not provide us } \\
\text { anything like dust bins to be used for our waste materials" (Nr 14). } \\
4 \ldots \ldots . \text { "There is little education on most of the things the local } \\
\text { authorities claimed they have planned for the communities and without } \\
\text { such education we do not understand most of the things they do. They } \\
\text { just come here and ask us to assist them to implement this policy or that } \\
\text { programme activities. But how can we participate effectively in } \\
\text { something that we do not understand? (Nr 13) } \\
5: \text { “....I find it hard to believe that simply going to meetings will make } \\
\text { me change what the authorities here will like to do. ...They do not give } \\
\text { us (rural communities) any proper information about the importance of } \\
\text { participating in this SWM process (Nr 8). }\end{array}$ \\
\hline
\end{tabular}




\begin{tabular}{|c|c|}
\hline & $\begin{array}{l}\text { 6: "Most communities have the misconception that getting the } \\
\text { community involved will only help health officials to have more } \\
\text { benefits from the central government. So more work needs to be done } \\
\text { on educating the people, but not enough have been done" (Nr 9) } \\
7: \text {....."Most of us do our best in devoting our time to make sure } \\
\text { programmes like SWM that have to be implemented in this community } \\
\text { get a better start, but often it is not enough. The authorities will say we } \\
\text { will come next week, but we will only see them two months later. No } \\
\text { information from them to us. So we are not always sure how things are } \\
\text { and what the next programme will be" (Nr } 4) \\
\text { 8: ..... Even if we make all efforts to attend these meetings, we do not } \\
\text { get any feedbacks let alone information on when and what we are going } \\
\text { to discuss in the next meeting so that we can prepare for it (Nr 14) }\end{array}$ \\
\hline $\begin{array}{l}\text { 2: } \\
\text { Disillusionment } \\
\text { among the } \\
\text { members }\end{array}$ & 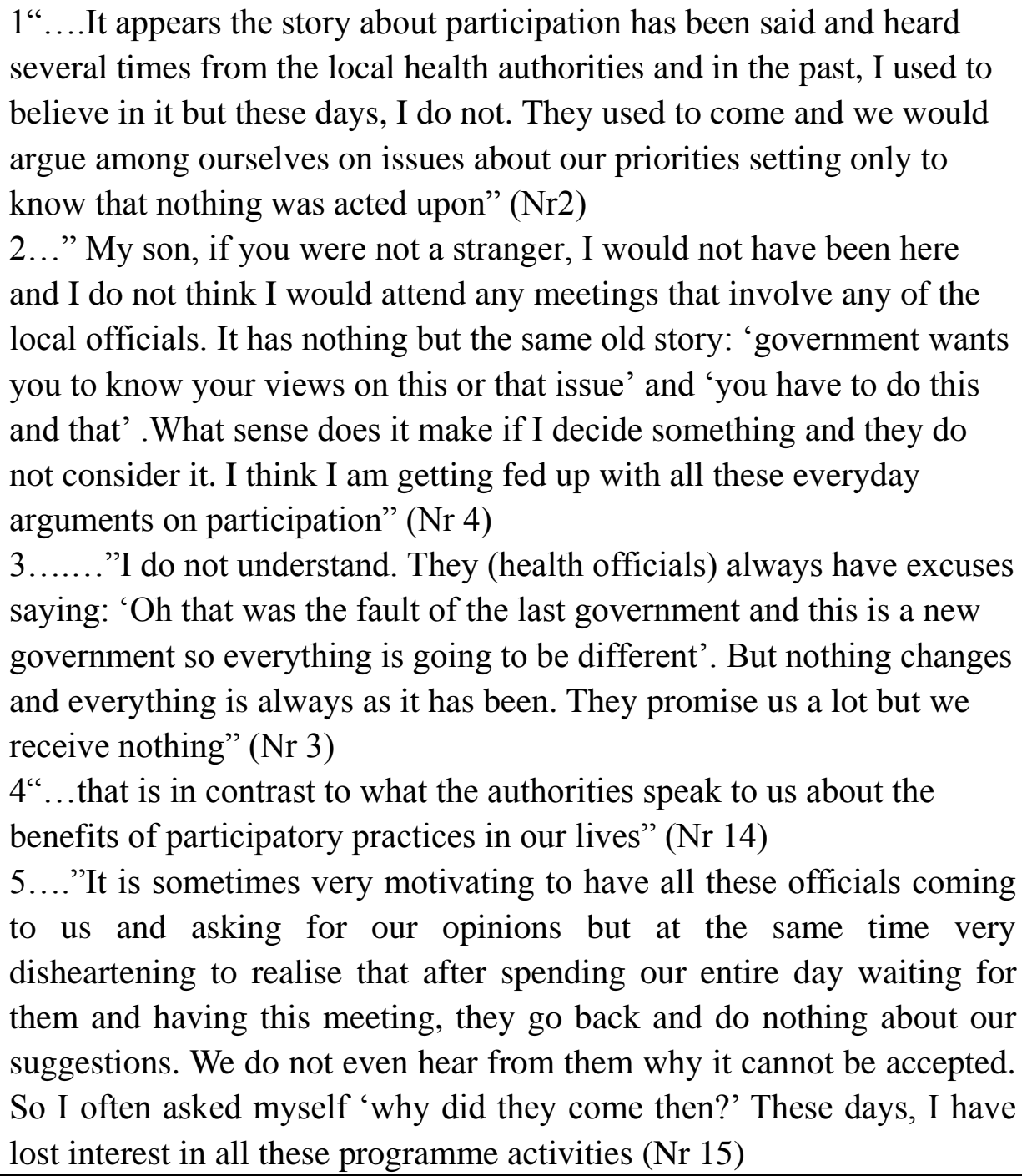 \\
\hline 3: Culture & $\begin{array}{l}\text { "1...."if you have a society which sees youth as solid waste cleaners } \\
\text { and expect the young ones to ensure proper sanitation within the } \\
\text { community, then indirectly you sow the seed of .....what I will say } \\
\text { 'disinterest' amongst we the elderly men to participate in any event that }\end{array}$ \\
\hline
\end{tabular}




\begin{tabular}{|c|c|}
\hline & 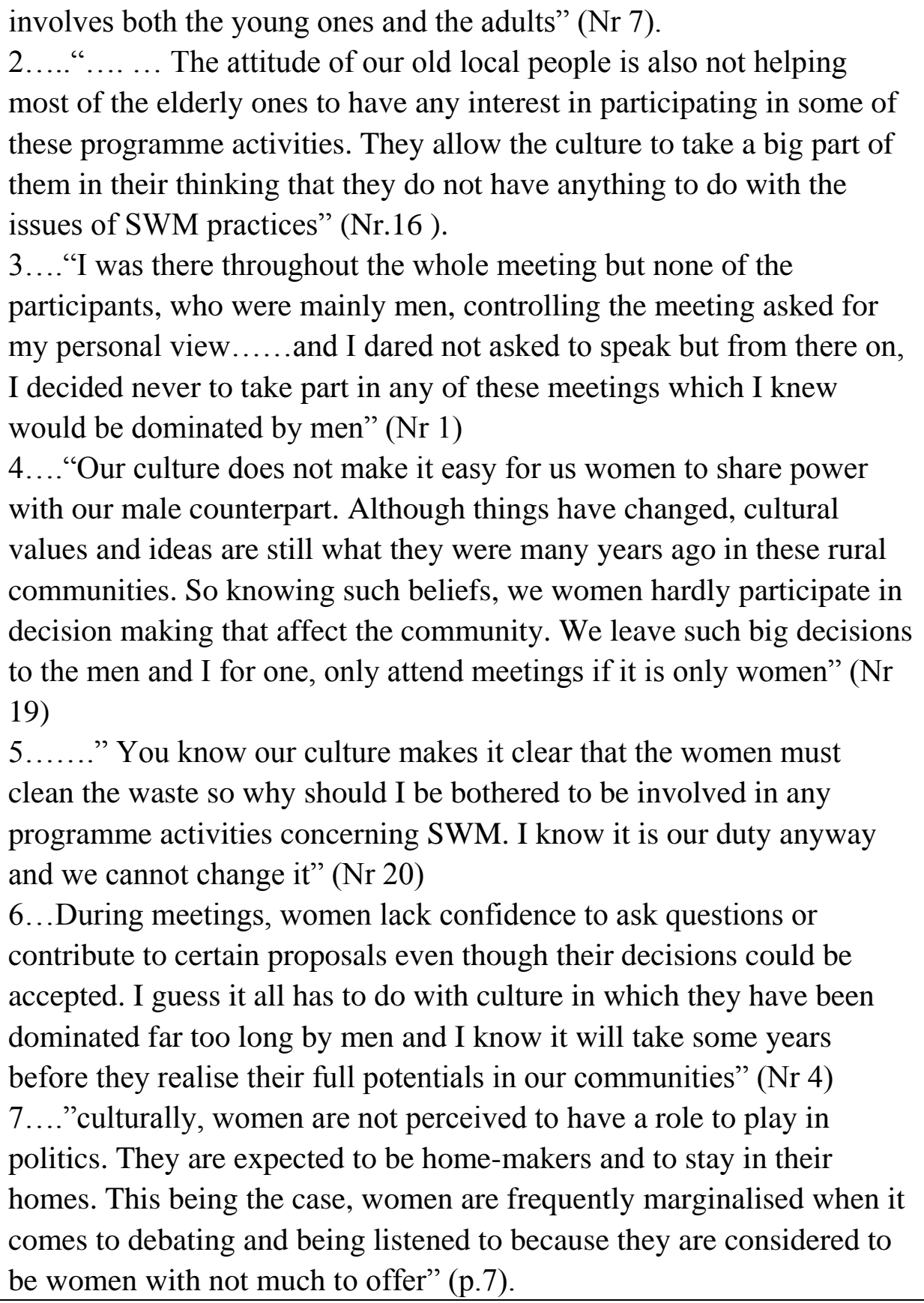 \\
\hline 4: Poverty & $\begin{array}{l}\text { 1..... "I always want to attend some of these meetings, but I do not have } \\
\text { money to go and walking from here to the place (district capital) is not } \\
\text { easy. It takes about four hours to get there and be back here. If I go, I } \\
\text { will be too tired to go to farm the next day. On the other hand, even if I } \\
\text { am able to go, I may not have enough money to buy containers for } \\
\text { managing the waste (Nr 11) } \\
2 . \text { ".....Sadly, they are never present in programme activities but I } \\
\text { understand their situation. They need to work twice as much as some of } \\
\text { us to be able to get their daily meal for themselves and their families" } \\
\text { (Nr 8) } \\
3 . \text { "...... In fact, majority of them are enthusiastic in taking part in }\end{array}$ \\
\hline
\end{tabular}




\begin{tabular}{|l|l|}
\hline $\begin{array}{l}\text { most of these programmes activities, but the poor economic } \\
\text { circumstances under which they find themselves makes it hard for them } \\
\text { to be good participants in some of the programmes" (Nr 18) } \\
\text { 4.. "Sometimes we get the information that tomorrow or this day, the } \\
\text { district health staff will come and talk to us about SWM, but I and my } \\
\text { wife cannot stop going to farm and wait for them. They usually come } \\
\text { the day prior to a market day or the market day itself, when I need to } \\
\text { bring my food stuffs from the farm to sell. So I cannot go and take part } \\
\text { in the meetings" (Nr 2). } \\
5 \ldots . . . . . \text { "For me, the most difficult time is when we are in the planting } \\
\text { season. It is so difficult to participate in these activities. I cannot } \\
\text { imagine myself not going to farm for food.....Where will I get money?" } \\
\text { (Nr 15). } \\
\text { 6........Over here farming is our major source of income. Joggling } \\
\text { between farming and participating in control programme activities is so } \\
\text { hard that we always have to make a choice. Doing both is an impossible } \\
\text { task and faced with a choice, we often choose to do the one that gives } \\
\text { us income to feed our families. It is simple as that" (Nr 12). }\end{array}$ \\
\hline
\end{tabular}

\subsection{Lack of Proper Support}

In all the study sites, majority of the interviewed community members (45\%) admitted that there had been lack of support from the local health authorities in so many areas. To most of these members, the health authorities often failed to pay attention to their interest and therefore disregarded any support that was needed to motivate the community members. For example, one interviewed community member said this:

"....the health officials have done anything to motivate us.... No educational campaign so most of us don't know what role we had to play ( $\mathrm{Nr} 12$ )

The above comment was shared by majority of the interviewed community members who perceived lack of support from local health authorities as one of the barriers to community participation.

During the FGDs, most of the members agreed that there had been little encouragement from the government as reflected in the following statements:

"We hardly get their support in terms of educational campaign but I believe .... there should be continuous education to inform us about the importance of SWM" (Nr 6)

...... "These days the health official do not provide us anything like dust bins to be used for our waste materials" (Nr 14).

Explicitly, most of the interviewed community members could not play an active role in the SWM practices, because not much effort has been made in helping them in terms of, for example, providing education and dust bins. Such insufficient education and coupled with lack of waste containers has not helped most of the community members to have positive 
views about the SWM that the government undertakes. The acknowledgement of this statement is reflected in the arguments made by some interviewed local residents who stated that:

......."There is little education on most of the things the local authorities claimed they have planned for the communities and without such education we do not understand most of the things they do. ...but how can we participate effectively in something that we do not understand? ( $\mathrm{Nr} 13$ )

"Many of our people usually rely on the information given to them by the government health workers or local volunteers ....Unfortunately, we tend to lack information on these programmes which creates skepticism..... and you know when people doubt the significance of something, they do not want to be involved or participate in it." (Nr 10).

Even if we make all efforts to attend these meetings, we do not get any feedbacks let alone information on when and what we are going to discuss in the next meeting so that we can prepare for it $(\mathrm{Nr} 11)$

These quotes could be interpreted in two ways. First, it indicated that more community members will participate and will have a meaningful role in local SWM policymaking process if local health authority comes closer to the people to provide them with the necessary information. The fact is that information is the source of knowledge which also contributes to power and without information, knowledge cannot be enriched (Mayo et al 2001). Thus, without proper information, not only will it be hard for community members to participate in policymaking process but it will also be hard for them to become partners on the same level with the health officials to decide on programme activities. This is consistent with the argument made by Alford (1975) who argued that: "community representatives do not have the information necessary to play an important political role; they do not know the levers of power, the interests at stake, and the actual nature of the operating institutions, and they do not have the political resources necessary to acquire that information" (p. 219)

Secondly, it also showed that in order to mobilise the community to participate in their health issues, there should be a creation of an atmosphere that fosters trusts, sense of belonging to the community and finally tangible support related to policy, guidelines and resources. Thus if participation can be perceived as encouraging and individuals' prospects of participating in policymaking process could be improved there is a need to have adequate and appropriate resources for the communities (Meleis, 1992; Sen, 1994). According to Brownlea, (1987), without sufficient resources participation is:"simply tokenism and does nothing to alter the knowledge balance, the skills balance, and the power balance in the community" (p. $6)$.

The implication from the above arguments is that asking the community to participate in programme activities is necessary but not sufficient. There should be strenuous efforts in providing community education on programme activities. This will help the community members to have an understanding of the process involved. Without a better understanding, some of the interviewees believe that most community members would find it difficult to 
know how participation in the policymaking process could empower them as well as help them to impact the policy outcome on SWM.

\subsection{Disillusionment}

Quite apart from lack of support from local health authorities, 16\% of the interviewed members revealed their disappointments on the repeated failures on the part of health officials to fully include the members in programme activities. From the views of some interviewed community members, the fact that the local health officials have for so many times failed to incorporate most of their priorities into the national programme activities has made them not to believe that local health authority could have local programme activities which could represent their needs and interests. For example, one local resident openly declared that:

"It appears the story about participation has been said and heard several times from the local health authorities and in the past, I used to believe in it but these days, I do not. They used to come and we would argue among ourselves on issues about our priorities setting only to know that nothing was acted upon" (Nr2)

To the community members, the issue of participation has been seen as yearly government 'festival'. The health officials come to them at a certain period of the year and once such a period was over, nothing would be heard again. The community members' disappointment was illuminating as exemplified in some of their arguments made during the FGDs:

..." ....if you were not a stranger, I would not have been here .... I think I am getting fed up with all these everyday arguments on participation" ( $\mathrm{Nr} 4)$

......."I do not understand. ..... nothing changes and everything is always as it has been. They promise us a lot but we receive nothing" ( $\mathrm{Nr} 3$ )

This extract illustrates a common theme. The community members see themselves being disappointed by health officials and the response of some interviewees reflected these low expectations. They argued that the community members had often been consulted and the communities have participated in the decision making process before and yet there had not been any evidence of increased local health support or benefits in solving the problem of SWM. According to one interviewee,

...."It is sometimes very motivating to have all these officials coming to us and asking for our opinions but at the same time very disheartening to realise that after spending our entire day waiting for them and having this meeting, they go back and do nothing about our suggestions.... These days, I have lost interest in all these programme activities (Nr 15)

This quote provides a vivid picture of the disillusionment of some of the interviewees and the kind of trust they have lost in local officials. The underlying cause has been due to their past experiences which have made them not to consider the whole idea of community participation seriously anymore. This is in line with the literature which indicates that:

“....the biggest deterrent to participation among citizens is their perception - or experienceof a lack of council response (Lowndes et al. 2001; p. 635). 


\section{MlMacrothink}

Environmental Management and Sustainable Development

ISSN 2164-7682 2019, Vol. 8, No. 2

Thus, while some may think that community members have been apathetic within their own community, most of the interviewed community members have different opinion. To some interviewed community members, the cause could be attributed to the disappointments from the local officials in terms of their persistent failures to support them and to fulfill their promises.

All in all, it can be concluded that ideas and the wishes of the environmental health authorities in Ghana on community participation are of little use if they cannot put into practice what they wish to achieve by providing the necessary support to the communities. By failing to provide the right support, the revitalization of the communities' confidence and skills become difficult (Wilcox, 1994). According to Wilcox, (1994), many participation processes involve entering into new forms of social lives and it is unrealistic to expect individuals or small groups suddenly to develop the capability to make complex decisions and become involved in major projects. What they need is providing them with the necessary support like training - or better still the opportunity to learn formally and informally, to develop confidence and trust in each other (Wilcox, 1994). This has been perceived by the communities to be lacking hence a barrier to participation.

\subsection{Culture}

Consistent with the literature, this study found that community participation in the study sites has been influenced by the local culture, which is also common in most Ghanaian regions (Wolke 1992; Ahorlu et al. 1997). For most (14\%) of the interviewed community members, one of the perceived barriers to participation has been the culture of the people that tends to influence the degree of participation in so many ways. Amongst those factors contributing to culture as a barrier included: elders conceptions on the roles of the youth and differences in gender roles. These are discussed in details below:

\subsubsection{Perceived Youth Responsibilities of Waste Management by Elders}

Several interviewed men spoke about the cultural responsibilities of keeping the community clean by the young ones within the community. Most of the elderly men argued that the youth were the ones to clean all the waste within the communities because traditionally cleaning are often reserved for the young ones and that the elders are not supposed to do anything as long as the young ones are around. This perception, according to most of the elderly interviewed men, sent a message that the neatness within the community was the responsibilities of the young ones which had the consequence of limiting their level of participation that they would otherwise aspire to. From the interview, there was a strong sense that the adult considered the youth to have more cultural obligation to SWM in the respective communities and therefore did not expect the elderly men to be part of the cleaning exercises. Most interviewed men spoke of how, for example, this kind of culture has affected their enthusiasm in participating in SWM by stating:

"if you have a society which sees youth as solid waste cleaners and expect the young ones to ensure proper sanitation within the community, then indirectly you sow the seed of ... 'disinterest' amongst we the elderly men to participate in any event that involves both the 
young and the adults" (Nr 7).

This was confirmed by one young person during the FGDs who stated that:

“.... ... The attitude of our old local people is also not helping most of the elderly ones to have any interest in participating in some of these programme activities. They allow the culture to take a big part of them in their thinking that they do not have anything to do with the issues of SWM practices" ( Nr.16).

The concern here is that, the adults culturally consider the youth to be responsible for SWM, therefore, they expect them to play a major role in it. The consequence has been in two ways. On one hand, the young ones are taken for granted by participating in the SWM exercise. On the other hand, the matured ones also do not see the need to take part in the SWM management. In effect, the participation in meaningful programme activities in any form by both young and the elderly has been limited. This has created a room for much expectation of what any of them should contribute in terms of decision making that will enhance the welfare of the community. In this case, it can be argued that even if there is an existence of opportunities for the young ones to take part in SWM practices, they are likely to be passive. In such a situation, Brownlea (1987) has argued that, even though the youths can be participants, they may, nonetheless, be:

"still observers; while being in the game, they are more reserve rather than players" (p.605).

The implication here is that, the society needs cultural change in terms of old peoples' attitude towards the youth so as to motivate the latter to participate. On the other hand, although, this assertion tends to confirm the argument of Camino (2000) who describes partnerships between youth and adults as 'breaking new ground' and 'new territory', the outcome can be less effective. The main reason is that when adults and youth are not used to new participatory ways of working, there can be a problem for the youths in adapting to new roles and responsibilities, especially if they have never had the chance to experience them before (Eames-Sheavly et al., 2007; Lekies et al., 2007). Frank (2006) also argued that the other way could also be true if the adults have not much understanding and experience working with young people. Such a situation could bring about lack of confidence and hesitation on the part of the adults on how to work together.

\subsubsection{Differences in Gender Roles}

Parallel to the above cultural barrier, it was also found that despite high level of social solidarity amongst communities and positive role in peoples' interpersonal networks, in most of these communities, the roles of the gender within the communities has been a source of a barrier to participation in SWM. During the interviews, it was revealed that most women were unwilling to be involved in the decision making process of SWM because of the way they were perceived by men. Most interviewed women complained about lack of recognition during meetings. For example, a woman who once attended one of the meetings spoke about the isolation she felt while in the meeting with the men who formed the majority of the participants. She declared: 
"I was there throughout the whole meeting but none of the participants, who were mainly men, controlling the meeting asked for my personal view...... and I dared not asked to speak... from there on, I decided never to take part in any of these meetings which I knew would be dominated by men" ( $\mathrm{Nr} 1)$

Another woman expressed her doubt about any possibility of a woman having any chance in making any meaningful contribution to decision making by stating that:

"Our culture does not make it easy for us women to share power with our male counterpart. Although things have changed, cultural values and ideas are still what they were many years ago in these rural communities. So knowing such beliefs, we women hardly participate in decision making that affect the community. We leave such big decisions to the men and I for one, only attend meetings if it is only women" (Nr 19)

Another woman reported by saying

...." You know our culture makes it clear that the women must clean the waste so why should I be bothered to be involved in any programme activities concerning SWM. I know it is our duty anyway and we cannot change it" (Nr 21)

These extracts suggest two significant common issues facing women in the study sites. The first is the acceptability of women in participating in policymaking process but with little or no power to make any great deal of impact. This reflects the opportunities available for both genders to participate in programme activities irrespective of the power imbalances. The second, an interwoven issue is the reluctance of male counterparts to surrender power to those that are considered as 'weak" or 'incapable'. Besides, the quotes also illustrate the importance of understanding how the idea of community participation itself can be socially constructed (Barnes et al., 2003). In this case, community participation, in the minds of the communities in the study sites is for strong people (men) who are to make decision but not for those who are 'weak' (women) (Ahorlu et al. 2006; Agyepong, 1992, Binka et al. 1997). In essence, based on culture, the women of Ghana have been assigned the role and responsibility of keeping the home and its immediate environment clean and as a result, the waste management has become one of their everyday jobs. These differences in perceptions alienate the women and highlights how men dominate and women have to respect such dominance in the study sites.

Thus with the experiences of exclusion as well as their perception of being the weaker ones in the society, women are less likely to be motivated to view themselves as welcomed or empowered members of the local community. Due to cultural norms which relegate women ideas to the background, the women lose interest in participating in SWM issues and they are unable to bring their ideas forward into the power domains. In this way, women feel less valued and ultimately believe that their suggestions would make no difference and their own cultural values (e.g. respect for men) has moved them into "an almost reflexically non-participatory way of thinking" (Brownlea, 1987, p. 607). Implicitly it can be said that the perceived culture of the male dominance of the communities in the study sites have contributed to a culture where the participation of the females as well as youths has been less 
than important. Some women and the youths appear to be put off in their involvement in public life because of their perception of the culture of male dominance. This suggests that much more work needs to be done on women who find themselves alienated when it comes to decision making in order to motivate them to participate.

\subsection{Poverty}

Based on the results of the interviews, another finding of this study was that of the high level of poverty amongst community members which had been a barrier to community participation.

In the study site, $25 \%$ of those interviewed admitted that there were two main factors, which, out of poverty, had compounded their ability to participate. These were: High cost of living and Poor source of income as explained in details below.

\subsubsection{High Cost of Living}

Most interviewed local members explained that although participation was beneficial to the communities, the high cost of living has deprived them of participating in most of the SWM activities. For example, most of them argued that there were costs (e.g. transport) involved which had to be incurred particularly during programme activities that needed to be held at the district level. In most cases, most people often had no money to travel to take part in community programme activities while others had no ability to buy waste management materials. Most of the interviewed community members disclosed their willingness to be part of such activities that usually took place at the district or sub-district level and yet they found it hard to be part of it. For example one member stated

.... "I always want to attend some of these meetings, but I do not have money to go and walking from here to the place (district capital) is not easy. It takes about four hours to get there and be back here. If I go, I will be too tired to go to farm the next day. On the other hand, even if I am able to go, I may not have enough money to buy containers for managing the waste ( $\mathrm{Nr} 11)$

The quote above raises very important point about the nature of people who often took part in the decision making process at the district level or are able to buy waste materials. Implicitly, the quote suggests that it is often the rich within the communities that not only represent the community but are able to buy waste materials. In that case, it is only those with money that can gain from participating in the SWM practices. Consequently, the poor usually have less chance to have their voices heard in discussions over SWM as well as have access to waste materials. This is consistent with Taylor (1999) who claims that "the things that disadvantage people make it harder for them to participate in group activities. This is not apathy. The pressures of bringing up a family on a low income leave little energy for the responsibilities of communitarianism" (p.4)

Thus, while most traditional analysis often blame communities' non-participations in programme activities on their culture of apathy, a broader understanding of the such non-participation could be attributed to barriers like poverty (Dorsner 2004; Schlozman, et. 
al., 1994; Taylor, 1999).

\subsubsection{Precarious Nature of the Communities' Livelihoods}

Besides cost of transportation, it was also revealed that due to poverty in both urban and rural areas, a number of community members work for long hours throughout the week just to be able to feed their families. This makes most members to have little or no time at all to participate in any programme activities relating to SWM practices. From the views of one local interviewees:

“.....Sadly, they are never present in programme activities but I understand their situation. They need to work twice as much as some of us to be able to get their daily meal for themselves and their families" (Nr 8)

".......majority of them are enthusiastic in taking part in most of these programmes activities, but the poor economic circumstances under which they find themselves makes it hard for them to be good participants in some of the programmes" (Nr 18)

These comments were confirmed by majority of the community members. For example:

During the FGDs among community members, most of the participants expressed their interests in being part of the programme activities but because of their poor circumstances, they could not participate. For example, some argued that:

"Sometimes we get the information that tomorrow or this day, the district health staff will come and talk to us about SWM, but I and my wife cannot stop going to farm and wait for them. .... when I need to bring my food stuffs from the farm to sell." (Nr 12).

... "For me,..I cannot imagine myself not going to farm for food. Where will I get money?" (Nr 15).

....... Over here joggling between farming and participating in control programme activities is so hard..... and faced with a choice, we often choose to do the one that gives us income to feed our families. It is simple as that" (Nr 12).

The core of these arguments is that work demands, and schedules perpetuated by poverty are major contributing factors that prevent rural community from participating in SWM programme activities. This is because their major priorities are to find means to feed their families, and not to spend time in meetings. This is consistent with the finding of a study in other part of West Africa, Senegal, where Dorsner (2004) found similar result. Overall, the general level of participation and its quality was found to be affected by lack of money particularly access to transportation in terms of cost and inability to afford basic necessities.

The implication here is that, with poverty the idea that through participation locally derived priorities are served and local communities are used effectively can sometimes be misleading (Brownlea, 1987). This is because participation does not portray the full story since it overlooks the operation of power relations at the local level which contributes to the recreation and amplification of more inequitable power balance between those who have money and those who have not. In this case, it is fair to say that the local community, given 
health development programmes like SWM initiatives, will find participation a double-edge sword, unless power is shared equally and the gap between potential and actual participation in terms of power to influence decision is narrowed. Thus as a result of poverty, the poor are less likely to participate in policymaking process than the rich (Kinsley et al. 1997; Dreier, 1996). According to Skidmore et al. 2006, such power imbalance can perpetuate a vicious cycle, which increases the problem and eventually dampens the interest of others participating in the programme acttivities. The authors argue that the cycle begins, on one hand, with non-participants expecting not to participate because they suppose others already will. On the other hand, existing participants believe they have to anticipate because if they do not, they expect nobody to be willing to participate. These anticipations ultimately becomes a self-fulfilling prophecy as the old-existing participants often perceive themselves as the right community members to take on such participatory responsibility.

\section{Conclusion}

The aim of this study has been to explore barriers to rural community participation in Solid Waste Management Programmes at the Asunafo North district in Brong Ahafo region of Ghana. The study finding indicated that a number of barriers prevent community members from participating in SWM which include: lack of support, disillusionment, culture and poverty. The findings indicate that almost all programmes that require community participation have been executed based on the beliefs of programme implementers or local health authorities. These effects are rooted from the 'top-down' approach which makes the administrators reluctant to share the information needed which eventually becomes part of the problems. This means that the public health officials create a 'gray area' or non-transparent system of resource allocation, e.g., dust bin provisions. Implicitly, there is lack of communication and information exchange which could play an important role of addressing barriers to SWM. The implication here is that there is scarcity of clear and dual communication channels in which the information is given from the government officials and the feedback is received from the affected community. Such scarcity has the potential to prevent community members to express their needs and desires to the government as well as preventing the community members from discussing and negotiating with the local government. From the community members' perspectives, it was realized that the local health authority has not been able to support them in their attempt to be active participants in the SWM practices. For example, there has not been adequate information provision, proper community education, persistent failure of the authority to fulfill its promise of including the communities' wishes or needs in their plans making the members to lose faith in the authorities. On the issue of culture, it was found that there was perceptual gap between the elderly men and the young ones since culturally the latter is perceived to be responsible for keeping the communities clean. In addition, it is revealed that due to culture, individual gender roles determine the extent of community members' participation in SWM. Women, in particular are mostly the ones who are often excluded from the decision making process in programme activities. Thus, beliefs and norms have considerable influence on participation in Ghana (Ahorlu, 1996; Agyepong, 1993). The last barrier to participation is found to be related to poverty which puts pressure on the community members to give priority to 
engaging in activities that give them their livelihood rather than participating in programme activities like SWM. Thus work demands and schedules caused by poverty are major contributing factors that prevent rural community from participating in programme activities.

\section{Recommendation}

Based on the findings the following recommendations are made:

- In order to improve participation there should be practical support from the various stakeholders such as the municipality, community-based organisations, micro enterprises and local leaders in the form of provision of education.

- There should also be creation of awareness for the need for SWM through better education on the issue of SWM especially on the need to recycle SW materials.

- For recycling of materials to be successful, there should be collection points for different types of waste within the communities as well as subsidizing the solid waste materials so that the poor can afford them.

- Finally the socio-economic lives of the people have to be improved by making better use of the resources of community members by boosting the small and micro-enterprises that are operating in the communities.

\section{Limitations and Future Outlook of the Study}

One limitation of this study is that the study involved only a very limited sample of respondents (30) from the entire district. As a result the conclusion that could be drawn from the study results could not be generalized as the views of these community members would not reflect the views of all the others in the district. Secondly, the views of the participants appeared to be fictions because the researcher had no means of verifying their true statements. The fact of the matter is that the qualitative approach is subjective characterized by feelings and personal views which were not quantitatively validated, nor were they tested for their stability or internal reliability. Thus it is believed that the approach cannot offer consistent and dependable data when compared to using quantifiable figures (Atkins and Wallac, 2012). In essence, not using numbers in this study makes it hard and impracticable to simplify findings and observations.

In view of this, in the near future, a mixed method (that is, both qualitative and quantitative) should be used. This will help the study results to be rich as both methods will complement each other's weaknesses. Also, future research should be conducted to address one of the limitations outlined in this study. For example, this study only concentrated on only one district alone. This means the views of the employees could not be generalized. As a result, the future research could extend the investigation to different districts and to obtain wider views of barriers on SWM so that the conclusion can be generalized within the context of Brong Ahafo region.

\section{References}

Agudelo, C., \& Carlos, A. (1983). Community participation in health activities: some concepts and appraisal criteria. [Online] Available: 
http://iris.paho.org/xmlui/handle/123456789/27359

Agyepong, I. A. (1992). Malaria: ethnomedical perceptions and practice in an Adangbe farming community and implications for control. Social Science \& Medicine, 35(2), 131-137. https://doi.org/10.1016/0277-9536(92)90160-R

Ahorlu, C. K., Dunyo, S. K., Asamoah, G., \&Simonsen, P. E. (2001). Consequences of hydrocele and the benefits of hydrocelectomy: a qualitative study in lymphatic filariasis endemic communities on the coast of Ghana.Actatropica,80(3), 215-221. https://doi.org/10.1016/S0001-706X(01)00159-0

Alford, R. R. (1975). Health Care Politics: Ideological and Interest Group Barriers to Reform. Chicago: University of Chicago Press. [Online] Available:

https://www.annualreviews.org/doi/abs/10.1146/annurev.so.01.080175.002241 ?journalCode= soc

Al-Maaded, M., Madi, N. K., Kahraman, R., Hodzic, A., \& Ozerkan, N. G. (2012). An overview of solid waste management and plastic recycling in Qatar. Journal of Polymers and the Environment, 20(1), 186-194. https://doi.org/10.1007/s10924-011-0332-2

Anderson, B., \& Communities, I. (1991). Reflections on the Origin and Spread of Nationalism. London, New York, 21993. [Online] Available:

https://scholar.google.com/scholar?hl=en\&as_sdt=0\%2C5\&scioq=Woman+in+the+Eyes+of+ God\%3A+Reclaiming+a+Lost+Identity \&q=Anderson\%2C+B.+\%281991\%29.+Imagined+co mmunities $\% 3 \mathrm{~A}+$ Reflections+on+the+origin+and+spread+of+nationalism+\%28Rev.+ed.\%29. +London\%3A+Verso.\&btnG=

Anderson, R. M., Gupta, S., \& May, R. M. (1991). Potential of community-wide chemotherapy or immunotherapy to control the spread of HIV-1. Nature, 350(6316), 356. https://doi.org/10.1038/350356a0

Arnstein, S. R. (1969). A ladder of citizen participation. Journal of the American Institute of planners, 35(4), 216-224. https://doi.org/10.1080/01944366908977225

Atkins, L., \& Wallace, S. (2012). Qualitative research in education. SAGE publications. https://doi.org/10.4135/9781473957602

Borongan, G., \& Okumura, S. (2010). Municipal waste management report: status-quo and issues in south east and East Asian countries. Copyright VAIT/UNEP Regional Resource Center for Asia and the Pacific, United Nations Environment Programme, Thailand, 1-43. [Online] Available:

https://scholar.google.com/scholar?hl=en\&as_sdt=0\%2C5\&q=Borongan $\% 2 \mathrm{C}+\% 26+O$ kumur $\mathrm{a} \% 2 \mathrm{C}+2010+$ waste $\& b \operatorname{tnG}=$

Brownlea, A. (1987). Participation: myths, realities and prognosis. Social Science \& Medicine, 25(6), 605-614. https://doi.org/10.1016/0277-9536(87)90085-2

Butterfoss, F. D. (2006). Process evaluation for community participation. Annu. Rev. Public Health, 27, 323-340. https://doi.org/10.1146/annurev.publhealth.27.021405.102207 
Camino, T. S., \& Malone, J. D. (2000). U.S. Patent No. 6,086,613. Washington, DC: U.S. Patent and Trademark Office. [Online] Available:

https://patents.google.com/patent/US6086613A/en

Campbell, C., \& Jovchelovitch, S. (2000). Health, community and development: Towards a social psychology of participation. Journal of Community \& Applied Social Psychology, 10(4), 255-270.

https://doi.org/10.1002/1099-1298(200007/08)10:4<255::AID-CASP582>3.0.CO;2-M

Chinamo, E. B. M. (2003, March). An overview of solid waste management and how solid waste collection benefits the poor in the city of Dar es Salaam. In CWG workshop on solid waste collection that benefits the urban poor, held in Dar esSalaam(pp. 8-14). [Online] Available:

https://scholar.google.com/scholar?lookup=0\&q=Chinamo,+2003+waste\&hl=en\&as_sdt=0,5

Chirico, J. (2009). There is No Such Thing as "Away": An Analysis of Sustainable Solid Waste Management Technologies. School of Public Policy Enterprise Innovation Institute Science, Technology, and Innovation Policy Program, 1-60. [Online] Available:

http://stip.gatech.edu/wp-content/uploads/2010/05/Sustainable-Waste-Management-Technolo gies_jchirico_updated-092309.pdf

Cofie, O., Bradford, A. A., \& Dreschel, P. (2006). Recycling of urban organic waste for urban agriculture. Cities farming for the future, Urban agriculture for sustainable cities, RUAF Foundation, IDRC and IIRR, 209-242. [Online] Available:

https://pdfs.semanticscholar.org/9947/89d7ba486fd78f07839e6783aedea6c7f7c6.pdf

Cohen, S. E., \& Syme, S. L. (1985). Social support and health. Academic Press. [Online] Available: https://psycnet.apa.org/record/1985-97489-000

Costello, J. C., Heiser, L. M., Georgii, E., Gönen, M., Menden, M. P., Wang, N. J., ... Kallioniemi, O. (2014). A community effort to assess and improve drug sensitivity prediction algorithms. Nature biotechnology, 32(12), 1202. https://doi.org/10.1038/nbt.2877

Creswell, J. W. (1998). Qualitative research and research design: Choosing among five traditions. London: Thousand Oaks. [Online] Available:

https://scholar.google.com/scholar?hl=en\&as_sdt=0\%2C5\&q=Creswell+\%281998\&btnG=

Cutter, S. L., Barnes, L., Berry, M., Burton, C., Evans, E., Tate, E., \& Webb, J. (2008). A place-based model for understanding community resilience to natural disasters. Global environmental change, 18(4), 598-606. https://doi.org/10.1016/j.gloenvcha.2008.07.013

Daskalopoulos, E., Badr, O., \& Probert, S. D. (1998). Resources, Conservation and recycling 24, 155-166. [Online] Available: https://www.scientific.net/AMR.518-523.3552

Dorsner, C. (2004). Social exclusion and participation in community development projects: evidence from Senegal. Social Policy \& Administration, 38(4), 366-382.

https://doi.org/10.1111/j.1467-9515.2004.00396.x

Dreier, O. (1999). Participation, intercontextuality, and personal trajectories. Challenges to 
theoretical psychology, 269-277. [Online] Available:

https://books.google.com.gh/books?hl=en\&lr=\&id=Tykd24ZY4ckC\&oi=fnd\&pg=PA269\&dq $=$ Dreier,+1996+participation\&ots=oj5QhbOgLb\&sig=LfYYtRVfVzDYtxJaMrRkvtnCvDg\&r edir_esc=y\#v=onepage \&q=Dreier\%2C\%201996\%20participation $\& \mathrm{f}=$ false

Field, J. M., \& Sroufe, R. P. (2007). The use of recycled materials in manufacturing: implications for supply chain management and operations strategy. International Journal of Production Research, 45(18-19), 4439-4463. https://doi.org/10.1080/00207540701440287

Frank, M. J. (2006). Hold your horses: a dynamic computational role for the subthalamic nucleus in decision making. Neural Networks, 19(8), 1120-1136.

https://doi.org/10.1016/j.neunet.2006.03.006

Gaventa, J., \& Pettit, J. (1980). Power and participation. Power and Powerlessness: Quiescence and Rebellion in an Appalachian Valley, 3-32. [Online] Available:

https://scholar.google.com/scholar?hl=en\&as_sdt=0\%2C5\&scioq=Woman+in+the+Eyes+of+ God $\% 3 \mathrm{~A}+$ Reclaiming+a+Lost+Identity \&q=Gaventa $\% 2 \mathrm{C}+1980+$ culture \&btnG $=$

Gerstein, H. C., Pogue, J., Mann, J. F. E., Lonn, E., Dagenais, G. R., McQueen, M., \& Yusuf, S. (2005). The relationship between dysglycaemia and cardiovascular and renal risk in diabetic and non-diabetic participants in the HOPE study: a prospective epidemiological analysis. Diabetologia, 48(9), 1749-1755. https://doi.org/10.1007/s00125-005-1858-4

Habitat, U. N. (2006).State of the World's Cities 2006/7. New York: United Nations. [Online] Available:

https://scholar.google.com/scholar?hl=en\&as_sdt=0\%2C5\&q=UN-HABITAT\%2C+2006\&bt $\mathrm{nG}=$

Hawe, P. (1994). Capturing the meaning of 'community'in community intervention evaluation: some contributions from community psychology. Health Promotion International, 9(3), 199-210. https://doi.org/10.1093/heapro/9.3.199

Hoornweg, D., \& Bhada-Tata, P. (2012). What a waste: a global review of solid waste management (Vol. 15, p. 116). World Bank, Washington, DC. [Online] Available: https://hypuco.ga/32ycy1mchch.pdf

Howlett, D., \& Nagu, J. T. (2001). Agricultural project planning in Tanzania. Development and Project Planning Centre, University of Bradford. [Online] Available:

http://agris.fao.org/agris-search/search.do?recordID=\%20US201300111776

Iyer, A., Poornima, D. G., \& Rao, M. N. (2001). Community Participation In Waste Management Experiences: of a Pilot Project in Bangalore, India. WASTE. [Online] Available:

https://scholar.google.com/scholar?hl=en\&as_sdt=0\%2C5\&q=Iyer+and+Anjana+2001\&btnG $=$

Jacob, K. S., Kumar, P. S., Gayathri, K., Abraham, S., \& Prince, M. J. (2007). The diagnosis of dementia in the community. International Psychogeriatrics, 19(4), 669-678. 
https://doi.org/10.1017/S1041610207005297

Kaseje, D. C. O., \& Sempebwa, E. K. (1989). An integrated rural health project in Saradidi, Kenya. Social Science \& Medicine, 28(10), 1063-1071.

https://doi.org/10.1016/0277-9536(89)90389-4

Krueger, A. B. (1988). The determinants of queues for federal jobs. ILR Review, 41(4), 567-581. https://doi.org/10.1177/001979398804100406

Labonte, R. N. (1997). Community development in the public health sector: The possibilities of an empowering relationship between the state and civil society. [Online] Available: https://elibrary.ru/item.asp?id=5570218

Lekies, K. S., Eames-Sheavly, M., MacDonald, L., \& Wong, K. J. (2007). Greener voices: Strategies to increase the participation of children and youth in gardening activities. Children Youth and Environments, 17(2), 517-526. [Online] Available:

https://www.jstor.org/stable/10.7721/chilyoutenvi.17.2.0517\#metadata_info_tab_contents

Lenox, M., \& King, A. (2004). Prospects for developing absorptive capacity through internal information provision. Strategic management journal, 25(4), 331-345.

https://doi.org/10.1002/smj.379

Lin, Y. P., Huang, G. H., Lu, H. W., \& He, L. (2008).Modeling of substrate degradation and oxygen consumption in waste composting processes. Waste Management, 28(8), 1375-1385. https://doi.org/10.1016/j.wasman.2007.09.016

Lincoln, Y. S., \&Denzin, N. K. (Eds.). (2000). The handbook of qualitative research. Sage. [Online] Available:

https://scholar.google.com/scholar?hl=en\&as_sdt=0\%2C5\&q=Denzin+\%26+Lincoln+\%2820 $00 \& b \operatorname{tnG}=$

Location of the study

https://www.google.com/search?client=firefox-b-d\&q=map+of+Asunafo+North+District+in+ Ghana

Lockett-Kay, J. E. (2005). Community participation in the establishment of a primary health organisation in the Horowhenua: a longitudinal case study. Unpublished PhD, Massey University, Palmerston North. [Online] Available:

https://scholar.google.com/scholar?hl=en\&as_sdt=0\%2C5\&scioq=Woman+in+the+Eyes+of+ God\%3A+Reclaiming+a+Lost+Identity\&q=Lockett-Kay\%2C+2005\&btnG=

Lowndes, V., Pratchett, L., \& Stoker, G. (2001). Trends in public participation: part 1-local government perspectives. Public administration, 79(1), 205-222.

https://doi.org/10.1111/1467-9299.00253

Marín, B. V. (2003). HIV prevention in the Hispanic community: Sex, culture, and empowerment. Journal of Transcultural Nursing, 14(3), 186-192.

https://doi.org/10.1177/1043659603014003005 


\section{Macrothink}

Environmental Management and Sustainable Development

ISSN 2164-7682 2019, Vol. 8, No. 2

Mayo, A. (2001). The human value of the enterprise. London: Nicholas Brealey Publishing. [Online] Available:

https://s3.amazonaws.com/academia.edu.documents/28362516/the-human-value-of-the-enter prise.pdf?AWSAccessKeyId=AKIAIWOWYYGZ2Y53UL3A\&Expires $=1553677678 \&$ Signa ture $=$ PUQKEOVLQQ1YyoSkNSeGkO\%2BwWQY\%3D\&response-content-disposition=inlin e\%3B\%20filename\%3DC_unleashed.pdf

McClellan, D. E., \& Kinsey, S. (1997). Children's Social Behavior in Relationship to Participation in Mixed-Age or Same-Age Classrooms. [Online] Available:

https://eric.ed.gov/?id=ED418771

Meleis, A. I. (1992). Community participation and involvement: theoretical and empirical issues. Health services management research, 5(1), 5-16.

https://doi.org/10.1177/095148489200500102

Merton, R. K. (1956). The Focused Interview: A Manual of Problems and Procedures, by Robert K. Merton, Marjorie Fiske [and] Patricia L. Kendall. Free Press. [Online] Available: https://scholar.google.com/scholar_lookup?hl=en\&publication_year=1990\&author=R.K.+Me rton\&author=M.+Fiske\&author=P.L.+Kendall\&title=The+Focused+Interview\%3A+A+Manu al+of+Problems+and+Procedures

Morgan, D. L. (2002). Focus group interviewing. Handbook of interview research: Context and method, 141-159. https://doi.org/10.4135/9781412973588.n10

Morrissey, A. J., \& Browne, J. (2004). Waste management models and their application to sustainable waste management. Waste management, 24(3), 297-308.

https://doi.org/10.1016/j.wasman.2003.09.005

Mukherjee, A., \& Lapre, M. W. (1998). Knowledge Driven Quality Improvement. Management Science, 44, 11. https://doi.org/10.1287/mnsc.44.11.S35

Ndiaye, S. M., Quick, L., Sanda, O., \& Niandou, S. (2003). The value of community participation in disease surveillance: a case study from Niger. Health Promotion International, 18(2), 89-98. https://doi.org/10.1093/heapro/18.2.89

Oteng-Ababio, M. (2014). Rethinking waste as a resource: insights from a low-income community in Accra, Ghana. City, Territory and Architecture, 1(1), 10.

https://doi.org/10.1186/2195-2701-1-10

Parry, G., Moyser, G., \& Day, N. (1992). Political participation and democracy in Britain. Cambridge University Press. https://doi.org/10.1017/CBO9780511558726

Pence, B., Nyarko, P., Binka, F. N., Phillips, J. F., \& Debpuur, C. (2001, August). The impact of the Navrongo Community Health and Family Planning Project on child mortality, 19932000.In Global Conference of the International Union for the Scientific Study of Population, Salvador, Brazil, August. [Online] Available:

http://archive.iussp.org/Brazil2001/s40/S43_P03_Pence.pdf

Peprah, K., Amoah, S. T., \& Achana, G. T. W. (2015). Assessing '3rs'Model in Relation to 
Municipal Solid Waste Management in Wa, Ghana. [Online] Available: http://udsspace.uds.edu.gh/handle/123456789/286

Rifkin, S. B. (1986). Lessons from community participation in health programmes. Health policy and planning, 1(3), 240-249. https://doi.org/10.1093/heapol/1.3.240

Saldana, L., \& DuBois, D. L. (2006). Youth reactions to participation in psychological assessment procedures. Journal of Clinical Child and Adolescent Psychology, 35(1), 155-162. https://doi.org/10.1207/s15374424jccp3501_14

Schlozman, K. L., Burns, N., \& Verba, S. (1994). Gender and the pathways to participation: The role of resources. The Journal of Politics, 56(4), 963-990.

https://doi.org/10.2307/2132069

Schübeler, P., Christen, J., \& Wehrle, K. (1996). Conceptual framework for municipal solid waste management in low-income countries (Vol. 9). St. Gallen: SKAT (Swiss Center for Development Cooperation). [Online] Available:

https://www.researchgate.net/profile/Vanessa_Massara/post/Do_you_know_any_model_on_c ost_effective_approach_to_urban_water_supply/attachment/59d61eb479197b807797d20c/A S\%3A273803236577289\%401442291187056/download/CWG\%20List.pdf

Schübeler, P., Christen, J., \& Wehrle, K. (1996). Conceptual framework for municipal solid waste management in low-income countries (Vol. 9). St. Gallen: SKAT (Swiss Center for Development Cooperation). [Online] Available:

https://www.researchgate.net/profile/Vanessa_Massara/post/Do_you_know_any_model_on_c ost_effective_approach_to_urban_water_supply/attachment/59d61eb479197b807797d20c/A S\%3A273803236577289\%401442291187056/download/CWG\%20List.pdf

Sen, R. (1994). Building community involvement in health care. Social policy, 24(3), 32-43. [Online] Available: https://europepmc.org/abstract/med/10135543

Shakya, S. M., \& Tuladhar, B. (2014). State of Municipal Solid Waste Management in the Municipalities of Nepal. In Municipal Solid Waste Management in Asia and the Pacific Islands (pp. 233-253). Springer, Singapore. https://doi.org/10.1007/978-981-4451-73-4_12

Sinha, A. M. M., \& Enayetullah, I. (2000). Community Based Solid Waste Mamagement: The Asian Experience, Papers and Proceedings of the Regional Seminar, 19-20 February 2000, Dhaka, Bangladesh. Waste Concern. [Online] Available:

https://scholar.google.com/scholar?hl=en\&as_sdt=0\%2C5\&q=Sinha+\%26+Enayetullah\%2C $+2000 \&$ btnG $=$

Skidmore, W. C., Linsenmeier, J. A., \& Bailey, J. M. (2006).Gender nonconformity and psychological distress in lesbians and gay men. Archives of sexual behavior, 35(6), 685-697. https://doi.org/10.1007/s10508-006-9108-5

Taylor, D. L., \& Bruns, T. D. (1999). Community structure of ectomycorrhizal fungi in a Pinusmuricata forest: minimal overlap between the mature forest and resistant propagule communities. Molecular Ecology, 8(11), 1837-1850. 


\section{Macrothink \\ Environmental Management and Sustainable Development \\ ISSN 2164-7682 2019, Vol. 8, No. 2}

https://doi.org/10.1046/j.1365-294x.1999.00773.x

United Nations Environmental Programme (UNEP). Towards a green economy: Pathways to sustainable development and poverty eradication. Geneva: UNEP; 2011. [Online] Available: http://www.unep.org/greeneconomy/Portals/88/documents/ger/ger_final_dec_2011/Green \%2 0EconomyReport_Final_Dec2011.pdf

Wilcox, D. (1994). Community participation and empowerment: Putting theory into practice. Rra Notes, 21, 78-82. [Online] Available:

https://books.google.com.gh/books?hl=en\&lr=\&id=Gqpls_s7WCAC\&oi=fnd\&pg=PA78\&dq =wilcox+1994+ladder+of+participation\&ots=YPSrYU4dU0\&sig=zCtLqUnIsCrujXeMj_2Tq 14--yc\&redir_esc=y\#v=onepage \&q=wilcox\%201994\%20ladder\%20of\%20participation \&f=f alse

Woelk, G. B. (1992). Cultural and structural influences in the creation of and participation in community health programmes. Social Science \& Medicine, 35(4), 419-424.

https://doi.org/10.1016/0277-9536(92)90334-M

Wolke, D. (1998). Psychological development of prematurely born children. Archives of disease in childhood, 78(6), 567-570. https://doi.org/10.1136/adc.78.6.567

Zaman, A. U. (2014). Measuring waste management performance using the 'Zero Waste Index': the case of Adelaide, Australia. Journal of Cleaner Production, 66, 407-419. https://doi.org/10.1016/j.jclepro.2013.10.032

Zarate, M. A., Slotnick, J., \& Ramos, M. (2008). Capacity building in rural Guatemala by implementing a solid waste management program. Waste management, 28(12), 2542-2551. https://doi.org/10.1016/j.wasman.2007.10.016

Zhu, D., Asnani, P. U., Zurbrugg, C., Anapolsky, S., \& Mani, S. K. (2007). Improving municipal solid waste management in India: A sourcebook for policymakers and practitioners.The World Bank. https://doi.org/10.1596/978-0-8213-7361-3

\section{Copyright Disclaimer}

Copyright for this article is retained by the author(s), with first publication rights granted to the journal.

This is an open-access article distributed under the terms and conditions of the Creative Commons Attribution license (http://creativecommons.org/licenses/by/3.0/). 